\title{
Clinical Efficacy and Nursing Experience of Treating Pulmonary Tuberculosis with Levofloxacin Combined with Anti-Tuberculosis Drugs
}

\author{
YAN LIANG, XUEQIN YANG, MEIFENG LIU, YAZHEN LI* AND Y. ZHANG ${ }^{1}$ \\ Department of Traditional Chinese Medicine, 1Department of Respiratory, The First Hospital of Jilin University, Changchun \\ 130000 , China
}

Liang et al.: Treatment of PTB with Levofloxacin Combined with Anti-Tuberculosis Drugs

\begin{abstract}
To observe the clinical efficacy of levofloxacin combined with anti-tuberculosis drugs in the treatment of pulmonary tuberculosis and explore effective nursing schemes. The 160 patients who had been clearly diagnosed with pulmonary tuberculosis in our hospital were selected as the study subjects. They were divided into study group and control group, each containing 80 cases. The control group was treated with pure anti-tuberculosis drugs, while the study group was treated with levofloxacin combined with other anti-tuberculosis drugs. In addition, the control group received general routine nursing, while the study group received comprehensive nursing. The treatment and nursing effects were compared between the two groups. The sputum tuberculomyces disappearance rate, cavity closing ratio, foci absorption rate and sputum tuberculomyces clearance time, cavity closing time, foci absorption time were $92.50 \%$, $97.50 \%, 95.00 \%,(5.34 \pm 1.29) \mathrm{mo},(5.31 \pm 1.20) \mathrm{mo},(5.03 \pm 1.65) \mathrm{mo}$ in study group, while that values were $75.00 \%, 80.00 \%, 77.50 \%,(7.80 \pm 2.16) \mathrm{mo},(7.69 \pm 2.21) \mathrm{mo},(7.59 \pm 2.39) \mathrm{mo}$ in the control group. This indicates that indicators in study group were significant better than those in control group $p<0.05$. The incidence of adverse reactions $(2.50 \%)$ were lower in the study group than in the control group $(15.00 \%)$, $\mathbf{p}<0.05$. The overall nursing satisfaction $(\mathbf{9 7 . 5 0} \%)$ was higher in the study group than in the control group $(75.00 \%), p<0.05$. Good clinical efficacy can be achieved using levofloxacin combined anti-tuberculosis drugs in the treatment of pulmonary tuberculosis and combined use of comprehensive nursing intervention program can significantly improve treatment effect.
\end{abstract}

Key words: Levofloxacin, anti-tuberculosis drugs, combination therapy, pulmonary tuberculosis, nursing intervention

Pulmonary tuberculosis (PTB) is a pulmonary infectious disease triggered by Mycobacterium tuberculosis, which poses a serious threat to human life and health. The infection source of Mycobacterium tuberculosis (tubercle bacillus) is mainly the tuberculosis (TB) patient who discharges bacterium and the Mycobacterium tuberculosis is spread through respiratory tract. Some healthy people infected with tubercle bacillus do not show signs of the disease, but the sign will appear once the body immunity drops ${ }^{[1]}$. In 1993, the World Health Organization declared global TB emergency condition, so TB has become a major public health problem around the world. Tubercle bacillus, belonging to Mycobacterium, appears as slightly curved or straight bacillus under microscope (fig. 1). Individual tuberculous Mycobacterium is in

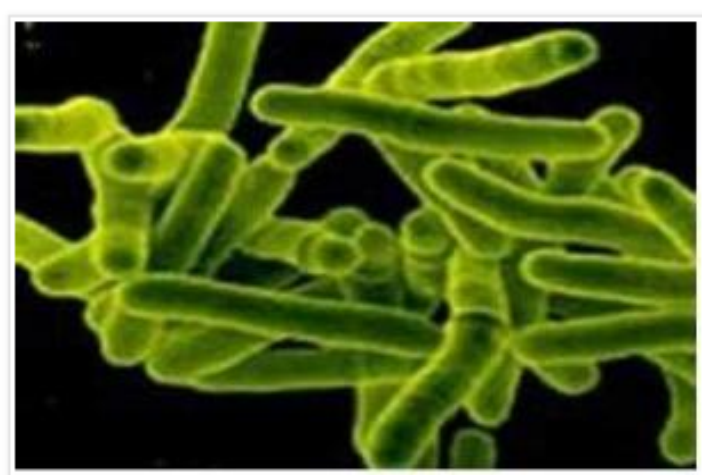

Fig. 1: Mycobacterium tuberculosis

V, Y shape or strip shape, short chain shape arrangement. As obligate aerobe, tubercle bacillus grows slowly. In recent years, the incidence of TB in the world (fig. 2) is still on the rise. Although there are many types of 


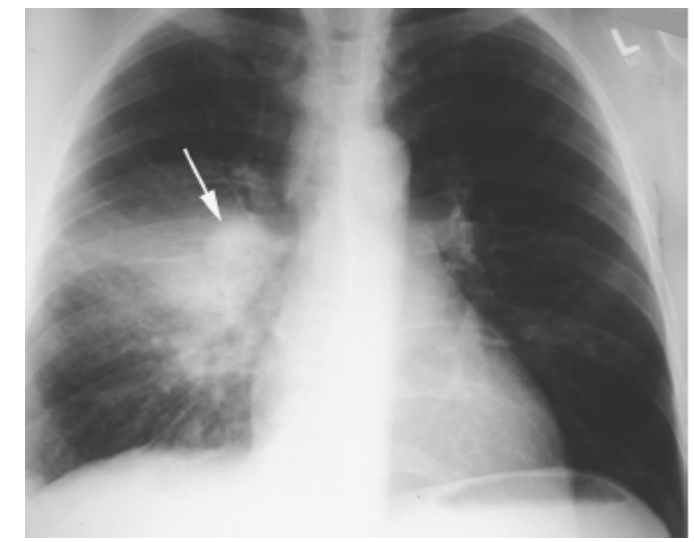

Fig. 2: Imaging manifestations of PTB

therapeutic drugs, their effects are different ${ }^{[2]}$. Levofloxacin is a typical quinolone antibiotic widely used in the treatment of PTB. As a quinolone class antibiotic, levofloxacin can specifically act on the bacteria deoxyribonucleic acid (DNA) rotational enzyme A subunit and push the realization of DNA rotational relaxation in the initial phase of DNA replication, allowing the newly synthesized deoxynucleotide chains to intertwine into loops, leading to degradation and death of bacterial DNA, so as to exert good antibacterial effect. This study observes the clinical efficacy of levofloxacin combined antituberculosis drugs in the treatment of PTB and proposes a scientific nursing scheme, which provides valuable guidance for clinical treatment practice. The 160 patients who had been clearly diagnosed with PTB in our hospital from June 2015 to May 2018 were selected as the study objects. All patients met the diagnostic criteria for PTB and serious liver and kidney dysfunction, epilepsy and pneumoconiosis were excluded ${ }^{[3]}$. There was no allergic case in this study. Patients and their families had the right to know about treatment and signed formal informed consent. This study was approved by the hospital ethics committee. The patients were randomly divided into study group and control group, each containing 80 cases. There were 42 men and 38 women in study group, with an average age of $(60.8 \pm 2.5) \mathrm{y}$ and an average onset time of $(0.8 \pm 0.2)$ mo. There were 43 men and 37 women in control group, with an average age of $(62.7 \pm 3.0)$ y and an average onset time of $(0.8 \pm 0.5)$ mo. There was no significant difference in the general information between two groups, $\mathrm{p}>0.05$. The control group was treated with anti-tuberculosis drug therapy, oral administration of isoniazid (produced by Yaodu Pharmaceutical Co., Ltd., national medicine permission number: H13022701, specification: $0.1 \mathrm{~g}$ /tablet) $0.3 \mathrm{~g}$, once a day; rifampicin (produced by Jiangxi Jiuhua
Pharmaceutical Co., Ltd, Chinese medicine permission number: H36020472, specification: $0.15 \mathrm{~g} /$ tablet) $0.45 \mathrm{~g}$, once a day; Oral administration of ethambutol (produced by Ningbo Tianheng Pharmaceutical Co., Ltd., national medicine permission number: H33022349, specification: $0.25 \mathrm{~g} /$ tablet) $0.75 \mathrm{~g}$, once a day; pyrazinamide (produced by Henan Fulin pharmaceutical factory, Chinese medicine permission number: H41022614, specification: $0.25 \mathrm{~g}$ /tablet) $0.5 \mathrm{~g}$, three times a day. The initial treatment at the intensive stage takes 2 mo and the retreatment takes 3 mo. The control group received general routine nursing, namely, health propaganda and education, answers to patient's problems, ward environment nursing for better comfort, instructions of medication on time, active treatment of adverse reactions, etc. On the basis of the above conventional anti-tuberculosis drug treatment regimen, the study group was further treated with levofloxacin. That is, oral administration of levofloxacin (produced by Shandong Lukang pharmaceutical group Saite Co., Ltd, national medicine permission number: H20046341, specification: $0.1 \mathrm{~g}$ ) $0.3 \mathrm{~g}$, once a day. Similarly, the initial treatment in the intensive stage took $2 \mathrm{mo}$ and the retreatment took 3 mo. The study group was treated with comprehensive nursing intervention. First, strengthen health education. Health education ran throughout the hospitalization since the patient was admitted. The patients were explained with pathogenic factors, medication knowledge, treatment scheme and results, matters needing attention of PTB through oral interpretation, health brochures and lectures to improve their treatment compliance. Second, implement humane psychological care. PTB patients may experience negative emotions such as anxiety, depression and disturbance owing to high treatment cost, long hospital stay, strong infectivity and isolation treatment. Nurses should make positive communication with them, instruct them to relax through listening to music, reading newspaper and book, watching video to divert attention and establish positive faith in treatment ${ }^{[4-6]}$. Third, do a good job of disinfection and isolation. Strictly implement insulation protective measures for respiratory infectious diseases, implement systems in visitation $^{[7]}$, disinfection and isolation as well as hand hygiene, separate clean area from pollution area, set up worker and patient channels with internal and outside corridor to reduce cross infection. In addition, illuminate the ward and corridor with ultraviolet lamp, explain the importance of disinfection and isolation to the patient and family member and prohibit spitting anywhere and smoking. Fourth, strengthen medication care. Follow 
standard principle namely, early, regular, joint, appropriate, whole course drug administration, implement directly observed treatment, short course (DOTS) principle, that is, strictly ensure that medicine is sent to the patient, taken by the patient before leaving, let patients receive regular chemotherapy, avoid medication errors ${ }^{[8]}$. Fifth, strengthen local skin care. During the patient's infusion treatment, strictly control the infusion speed, meanwhile, choose the best vein, select thick and straight blood vessel with good flexibility, observe the puncture position, protect and reasonably use vein. Sixth, provide good nursing for adverse reactions. The general adverse reactions during the treatment usually include gastrointestinal tract reaction (loss of appetite, nausea, vomiting, etc.), liver function damage, allergic reaction (rash), high uric acid reaction, etc. Nurses should actively monitor patient's vital signs and observe patient reaction after drug use, immediately report to the doctor for processing once abnormalities occur. For the two groups, make statistics of sputum tuberculomyces disappearance rate, cavity closing ratio, foci absorption rate and sputum tuberculomyces clearance time, cavity closing time, foci absorption time, as well as incidence of adverse reactions and overall nursing satisfaction (very satisfactory: 90-100 points, satisfactory: $70-89$ points, unsatisfactory: 69 points and below). The statistical analysis software used was SPSS 21.0. Where, the measurement data were expressed by average \pm mean $(\overline{\mathrm{x}} \pm \mathrm{s})$, and $\mathrm{t}$ was used for group comparison. The count data is expressed in natural number (n) and percentage $(\%)$ and chi square was used for group comparison. $\mathrm{p}<0.05$ indicates statistical value. As shown in Table 1, observation of sputum tuberculomyces disappearance, cavity closing and foci absorption between the two groups shows more significant advantage of study group over control group in the indicators, $\mathrm{p}<0.05$, with statistical significance. The comparison of one patient's situation before and after treatment is shown in fig. 3 below. According to Table 2 below, the incidence rate of adverse reactions is lower in the study group than in the control group, $\mathrm{p}<0.05$, with statistical significance. According to Table 3, overall nursing satisfaction is higher in the study group than the control group, $\mathrm{p}<0.05$, with statistical significance. At present, the incidence of multidrug resistant tuberculosis (MDR-TB) is on rise in China, attracting higher attention from more and more clinicians and experts. There are many drugs to treat PTB in clinical practice, but with great difference. Studies have shown that single use of anti-tuberculosis drugs such as isoniazid has drawbacks like unreasonable schemes and multiple side effects and will reduce patient's treatment compliance ${ }^{[9,10]}$. Abundant clinical practices have shown that, levofloxacin can achieve better results in the treatment of MDR-TB. Levofloxacin belongs to quinolone antibiotics as ofloxacin R-isomer, which can specifically act on bacterial DNA gyrase subunit A, promote DNA rotational relaxation in the initial stage of DNA replication, so that the new synthetic deoxynucleotide chains and fundamental chains entangle with each other or form a ring, causing bacterial DNA degradation and death and displaying good antibacterial effect. At the same time, levofloxacin treatment has high safety, with no serious adverse reactions. In addition, scientific and effective nursing programs should be adopted during the treatment to improve adjuvant treatment effect ${ }^{[11,12]}$. In this study, the study group is treated with comprehensive nursing intervention including strengthened psychological nursing, health education, medication guide, isolation, disinfection and local skin nursing, adverse reaction nursing and so on and better nursing service is provided. According to the results, comparison of sputum tuberculomyces disappearance rate, cavity closing ratio, foci absorption rate and sputum tuberculomyces clearance time, cavity closing time, foci absorption time reveals significant advantage of study group over the control group, $\mathrm{p}<0.05$. Moreover, the study group has higher overall nursing satisfaction and lower rate of adverse reactions, fully demonstrating that application of levofloxacin combined anti-tuberculosis drugs plus scientific nursing intervention measures can help

TABLE 1: COMPARISON OF SPUTUM TUBERCULOMYCES DISAPPEARANCE, CAVITY CLOSING AND FOCI ABSORPTION BETWEEN THE TWO GROUPS

\begin{tabular}{lccccc}
\hline Group & $\begin{array}{c}\text { Sputum } \\
\text { tuberculomyces } \\
\text { disappearance rate (\%) }\end{array}$ & $\begin{array}{c}\text { Cavity } \\
\text { closing rate } \\
(\%)\end{array}$ & $\begin{array}{c}\text { Foci } \\
\text { absorption } \\
\text { rate (\%) }\end{array}$ & $\begin{array}{c}\text { Sputum } \\
\text { tuberculomyces } \\
\text { clearance time (mo) }\end{array}$ & $\begin{array}{c}\text { Cavity closing Foci absorption } \\
\text { time (mo) }\end{array}$ \\
\hline $\begin{array}{l}\text { Study group } \\
(\mathrm{n}=80)\end{array}$ & $74(92.50)$ & $78(97.50)$ & $76(95.00)$ & $5.34 \pm 1.29$ & $5.31 \pm 1.20$ \\
time $(\mathrm{mo})$
\end{tabular}


www.ijpsonline.com

TABLE 2: COMPARISON OF ADVERSE REACTIONS BETWEEN THE TWO GROUPS [n (\%)]

\begin{tabular}{lccccc}
\hline Group & Case number & Dizziness & $\begin{array}{c}\text { Nausea and } \\
\text { vomiting }\end{array}$ & Loss of appetite & $\begin{array}{c}\text { Incidence rate of adverse } \\
\text { reactions }\end{array}$ \\
\hline Study group & 80 & 1 & 1 & 0 & $2(2.50)$ \\
Control group & 80 & 4 & 5 & 3 & $12(15.00)$ \\
$\mathrm{X}^{2}$ & & & & 6.80 \\
$\mathrm{p}$ & & & & $<0.05$ \\
\hline
\end{tabular}

TABLE 3: COMPARISON OF OVERALL NURSING SATISFACTION BETWEEN THE TWO GROUPS [n (\%)]

\begin{tabular}{lccccc}
\hline Group & Case number & Very satisfied & Satisfied & Dissatisfied & Overall satisfaction \\
\hline Study group & 80 & 60 & 18 & 2 & $78(97.50)$ \\
Control group & 80 & 38 & 22 & 20 & $60(75.00)$ \\
$\mathrm{x}^{2}$ & & & & & 11.56 \\
$\mathrm{p}$ & & & & & $<0.05$ \\
\hline
\end{tabular}

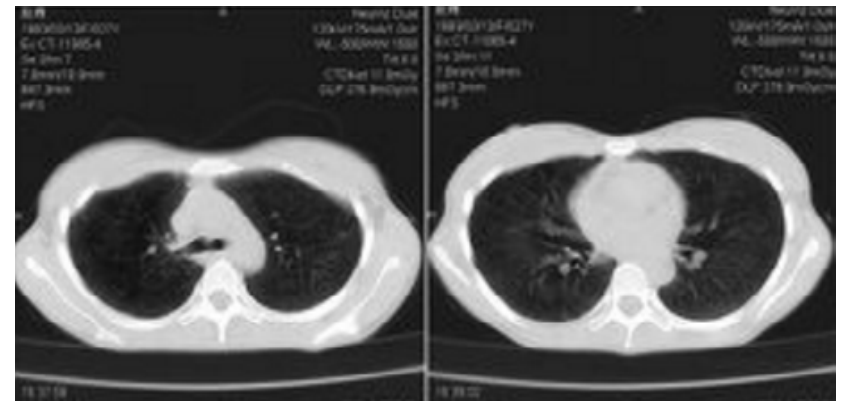

Fig. 3: Imaging comparison of one study group patient before and after treatment

elevate patients overall treatment effect. By comparing the two groups of patients in terms of sputum TB negative rate, cavity closure rate, lesion absorption rate, sputum TB negative time, cavity closure time and lesion absorption time, it can be known the indicators in study group were significant better than those in control group, $\mathrm{p}<0.05$. Patients in the study group had higher overall nursing satisfaction and lower adverse reaction rate, which fully demonstrated that the combined application of levofloxacin and anti-tuberculosis drug, assisted by scientific nursing interventions, could help patients to improve the overall treatment effect. This is consistent with the research results of Tumaini Nagu (Tumaini et al., 2017) and Cantey (Cantey et al., 2016). To sum up, treatment of PTB with levofloxacin plus anti-tuberculosis drugs can receive good clinical efficacy and joint comprehensive nursing intervention can significantly improve treatment effect. Therefore, it's worth a lot of promotion and application.

\section{Conflicts of Interest:}

The authors declared no conflict of interest.

\section{REFERENCES}

1. Sun Y, Zhang G. Diagnostic value of color doppler ultrasound in gynecological acute abdomen. Spec Health 2021;26:152

2. Cai ZY. Application value of color Doppler ultrasound in the diagnosis of gynecological acute abdomen. Contemp Med Forum 2021;19(1):121-2

3. Sun H. application of ultrasonography in clinical diagnosis of gynecologic acute abdomen. Contemp Med 2016;13:58.

4. Chen X. Application of ultrasonography in clinical diagnosis of gynecologic acute abdomen. For All Health 2016;22(7):197.

5. Miao B. Analysis of application of ultrasonography in clinical diagnosis of gynecologic acute abdomen. Med Forum 2016;22(5):646-7.

6. Zhao JP. Application analysis of ultrasound imaging technology in clinical diagnosis of acute abdomen in obstetrics and gynecology. Inner Mongol J Traditi Chin Med 2014;10:889.

7. Wang X,Ku M, De W, Qin L, Wa TB, Li P.Analysis of application of ultrasonography in clinical diagnosis of gynecologic acute abdomen. Chin J Mod Drug Appl 2013;11(15):51-2.

8. Zhao LM, Zhang GF. Application of three dimensional ultrasound in gynecological acute abdomen. Gen J Stomatol 2020;7(2):133-5.

9. Shang $\mathrm{RM}$, Kong $\mathrm{MG}, \mathrm{Xu} \mathrm{XW}$. Application value of transabdominal ultrasound combined with transvaginal ultrasound in the diagnosis of gynecological acute abdomen. Chin J Clin Ration Drug Use 2020;13(28):167-8

10. Wang XF. Study the clinical application value of abdominal ultrasound combined with vaginal ultrasound in the diagnosis of gynecologic acute abdomen. Women's Health Res 2020;(17):192-3

11. Hou CX. Study on the value of transvaginal ultrasound combined with abdominal ultrasound in the diagnosis of gynecological acute abdomen. Mod Med Imagelogy 2019;28(1):149-50.

12. Yan LM. Clinical application of ultrasonography in diagnosis and differential diagnosis of gynecological acute abdomen. J Imaging Res Med Appl 2018;2(23):143-4.

This is an open access article distributed under the terms of the Creative Commons Attribution-NonCommercial-ShareAlike 3.0 License, which allows others to remix, tweak, and build upon the work non-commercially, as long as the author is credited and the new creations are licensed under the identical terms

This article was originally published in a special issue, "Evolutionary Strategies in Biomedical Research and Pharmaceutical Sciences" Indian J Pharm Sci 2021:83(3)

Spl issue;202-205 